\title{
MEMPERKUAT MOTIVASI BELAJAR DAN PERENCANAAN KARIER DI KELURAHAN PONDOK BENDA
}

\author{
Widia Astuti, Gatut Dradjad Purwoko, Senen, Eko Sudarso, Thaharuddin
}

Dosen Ekonomi Fakultas Ekonomi Universitas Pamulang

Email dosen01265@unpam.ac.id, dosen00612@unpam.ac.id,dosen01888 @unpam.ac.id ,dosen02070@unpam.ac.id dosen02091@unpam.ac.id

\begin{abstract}
ABSTRAK
Tujuan dari kegiatan Pengabdian kepada Masyarakat ini adalah untuk membantu sebagian masyarakat khususnya Remaja untuk mengatasi permasalahan tentang perencanaan karier setelah sebelum dan setelah menyelesaikan pendidikan.

Kegiatan Pengabdian kepada Masyarakat ini dilakukan dengan memberikan bantuan pengetahuan untuk membangun pola pikir yang kreatif untuk menciptakan peluangpeluang baru yang berguna untuk meningkatkan sumber daya manusia itu sendri.

Hasil dari kegiatan Pengabdian kepada Masyarakat ini yaitu masyarakat mengetahui bahwa merencanakan karier sejak dini akan membuat motivasi dan pengembangan diri lebih optimal.
\end{abstract}

\section{Kata kunci : Remaja, perencanaan karier dan motivasi}

\begin{abstract}
ABSTRAC
The purpose of this Community Service activity is to help part of the community, especially adolescents, to overcome problems regarding career planning after before and after completing education.

This Community Service activity is carried out by providing knowledge assistance to build a creative mindset to create new opportunities that are useful for increasing human resources themselves.

The result of this Community Service activity is that the community knows that planning a career from an early age will make motivation and self-development more optimal.
\end{abstract}

Keywords: Youth, career planning and motivation

\section{PENDAHULUAN}

Karena masih banyaknya warga yang masih berstatus Pelajar dan menjalani pembelajaran daring atau sistem pembelajaran jarak jauh (PJJ).Sistem Pembelajaran Jarak Jauh (PJJ) secara daring di masa pandemi korona masih jauh dari kata ideal. Berbagai pihak mendesak adanya langkah konkrit dalam mengatasi berbagai persoalan agar siswa dan guru tidak terus menjadi korban. ada banyak kendala yang dihadapi masyarakat ketika metode ini 


\section{JURNAL ABDIMAS

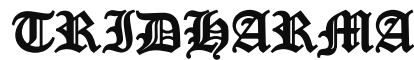

diterapkan, utamanya terkait infrastruktur pendidikan secara daring yang belum merata, bahkan di Ibukota Jakarta sekalipun, Kendala-kendala itu sudah menjadi keluhan merata dimana-mana. Persoalan lain yang perlu segera diatasi adalah kurikulum pendidikan yang tidak adaptif dengan sistem PJJ. Sebab, dengan kurikulum yang diterapkan saat ini, tanpa adanya kendala dari infrastruktur pendidikan pun pelaksanaan PJJ akan tetap bermasalah.

Dalam kegiatan belajar mengajar secara daring di berbagai daerah masih banyak kendala.Mulai dari tertinggalnya materi pembelajaran siswa, penugasan yang terlalu menumpuk, hingga orang tua tidak bisa optimal mendampingi anak selama PJJ. Di sisi lain, subsidi bagi para siswa dan guru untuk melaksanakan PJJ sendiri belum terjadi secara merata."Ada beberapa wilayah yang kepala sekolahnya belum merelokasikan Dana Bantuan Operasional Sekolah (BOS) untuk subsidi kuota internet siswa dan guru," jelasnya.

Jika kondisi ini dibiarkan berlarutlarut, maka disparitas kesenjangan kualitas pembelajaran dan pendidikan terhadap pelajar akan semakin timpang. Hanya mereka yang mampu mengakses pendidikan di tengah pandemi lah yang akan terus berkembang.Pembelajaran online dilakukan dengan memanfaatkan teknologi khususnya internet. Pemvelajaran online dilakukan dengan sistem belajar jarak jauh, dimana Kegiatan Belajar dan Mengajar (KBM) tidak dilakukan secara tatap muka. Pembelajaran dilakukan dengan menggunakan media, baik media cetak (modul) maupun non cetak (audio/video), komputer/internet, siaran radio dan televisi.

Pada pembelajaran online, peserta didik dapat menjadi kurang aktif dalam menyampaikan aspirasi dan pemikirannya, sehingga dapat mengakibatkan pembelajaran yang menjenuhkan. Seorang siswa yang mengalami kejenuhan dalam belajar akan memperoleh ketidakmajuan dalam hasil belajar. Oleh karena itu, diperlukan pendorong untuk menggerakkan menggerakan siswa agar semangat belajar sehingga dapat memiliki prestasi belajar. Semangat belajar dapat dimiliki dengan meningkatkan motivasi belajar. Motivasi belajar adalah sebuah penggerak atau pendorong yang membuat seseorang akan tertarik kepada belajar sehingga akan belajar secara terus-menerus. Motivasi yang rendah dapat menybabkan rendahnya keberhasilan dalam belajar sehingga akan merendahkan prestasi belajar siswa.

\section{RUMUSAN MASALAH}

1. Tingkat kesadaran Remaja setempat yang kurang baik dalam perencanaan karier sejak dini.

2. Sebagian masyarakat sudah tidak peduli dengan Pencencanaan karier.

3. Semangat sebagian Remaja yang sudah sangat menurun karena situasi pandemi ini.

4. Keterbatasan sebagian masyarakat dalam mengembangkan ide dan kreativitasnya dalam pengembangan karier .

\section{TUJUAN PELAKSANAAN}

1. Bersama Kelurahan Pondok benda 


\section{JURNAL ABDIMAS

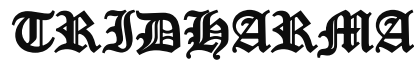

membantu meningkatkan kesadaran Remaja setempat untuk mengikuti berbagai pelatihan dan memotivasi dalam belajar untuk pengembangan karier

2. Bersama Kelurahan Pondok Benda membantu membuka mindset remaja untuk merencanakan karier sejak dini.

3. Bersama Kelurahan Pondok benda meningkatkan kekuatan moril sebagian masyarakat yang sudah sangat menurun .

4. Bersama Kelurahan Pondok Benda membantu masyarakat dalam membangun pola pikir agar Remaja dapat mengembangkan ide dan kreativitasnya dalam perencanaan karier.

\section{TINJAUAN PUSTAKA}

Karier adalah sebuah kata dari bahasa Belanda; carriere adalah perkembangan dan kemajuan dalam pekerjaan seseorang. Ini juga bisa berarti jenjang dalam sebuah pekerjaan tertentu.

Karier merupakan istilah yang didefinisikan oleh Kamus Besar Bahasa Indonesia sebagai perkembangan dan kemajuan baik pada kehidupan, pekerjaan atau jabatan seseo rang. Karier biasanya pekerjaan yang dimaksud adalah pekerjaan yang mendapatkan imbalan berupa gaji maupun uang.

Karena pilihan karier sering tidak jelas dan sulit, terdapat beberapa konsultan karier untuk panduan karier dan mereka memberikan bantuan orang perorang dan kelompok dalam eksplorasi dan pengambilan keputusan yang terkait dengan pilihan kerja, yang terus ke dunia kerja maupun pelatihan profesi lanjutan.

\section{Langkah Berikut Untuk Memilihan Karier yang Tepat}

\section{Menilai Diri Sendiri}

Sangat penting untuk belajar menilai tentang diri sendiri sebelum Anda memilih karir yang tepat. Anda harus memahami minat, keterampilan, bakat, dan kepribadian untuk memilih pekerjaan yang cocok dilakukan. Anda bisa menggunakan tes atau alat yang bermanfaat untuk mengumpulkan informasi tentang kepribadian dan selanjutnya bisa menghasilkan daftar pekerjaan yang cocok dengan kepribadian tersebut. Atau Anda juga bisa meminta bantuan dari konselor tentang pilihan karir yang tepat untuk Anda lakukan.

\section{Segera Membuat Daftar Pekerjaan}

Anda sudah mendapatkan daftar pekerjaan yang sesuai, maka inilah saatnya untuk membuat pilihan karir yang menarik minat.

\section{Pahami Dengan Baik Deskripsi Pekerjaan Tersebut}

Setelah membuat daftar pekerjaan terpilih, maka Anda sudah bisa memiliki pilihan karir yang lebih spesifik.Lanjutkan dengan mencari tahu deskripsi pekerjaan, persyaratan pendidikan, pelatihan yang diperlukan agar bisa mendapatkan karir di bidang tersebut.Agar memotivasi Anda tidak ada salahnya untuk mencari informasi yang berkaitan tentang propsek pekerjaan di masa depan dan pendapatan yang bisa dihasilkan.

\section{Membuat Daftar Pekerjaan yang Terpilih}

Berdasarkan informasi yang Anda temukan berkaitan tentang pelatihan, prospek pekerjaan, rata-rata pendapatan. Pada kesempatan ini, Anda sudah 


\section{JURNAL ABDIMAS

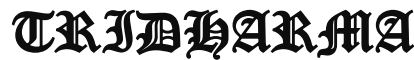

memahami dengan baik apa saja daftar pekerjaan yang terpilih. Anda bisa membuang pekerjaan dengan tugas yang tidak menarik minat, karir yang memiliki prospek yang lemah di masa depan, atau potensi pendapatan yang rendah. Anda juga bisa menyingkirkan pekerjaan yang membuat Anda tidak bisa memenuhi persyaratan pendidikan, keterampilan, dan lain sebagainya.

\section{Tentukan Pilihan Karir yang Diinginkan}

Setelah semua hal di atas sudah dilakukan, maka inilah saatnya untuk membuat pilihan karir yang akan dijalankan. Segera pilih pekerjaan yang menurut Anda bisa memberikan kepuasan berdasarkan informasi yang sudah dikumpulkan.

\section{Identifikasi Tujuan yang Anda Raih}

Setelah pilihan karir sudah ditentukan, maka Anda bisa mulai mengidentifikasikan tujuan jangka pendek dan panjang. Tujuan jangka panjang adalah tujuan yang membutuhkan waktu sekitar $3-5$ tahun untuk mencapainya. Sedangkan tujuan jangka pendek membutuhkan waktu sekitar 6 bulan sampai 3 tahun untuk mencapainya. Tujuan yang sudah ditetapkan akan membantu Anda untuk sukses di dalam karir yang dipilih. Contoh sederhananya seperti ini, Anda memiliki tujuan jangka panjang untuk menyelesaikan pendidikan yang disyaratkan agar bisa menempuh jalur karir tersebut. Sedangkan tujuan jangka pendek adalah mulai mendaftar perguruan tinggi yang berkualitas, mengikuti program magang, atau mengikuti pendidikan serta pelatihan yang mendukung. Penjelasan di atas membuat kita sadar bahwa pendidikan yang baik merupakan salah satu persyaratan penting agar bisa mendapatkan karir yang diinginkan. Belajar di jurusan yang sesuai dengan pilihan karir merupakan salah satu cara mendidik diri sendiri. Hanya saja banyak masyarakat terkendala dengan biaya pendidikan tinggi yang mahal dan bisa memberatkan kondisi keuangan keluarga mereka.Saat ini terjadi, impian untuk mewujudkan karir yang diinginkan bisa hilang hanya karena biaya yang mahal. Apa yang harus dilakukan saat ini terjadi?

\section{Menulis Rencana Kerja Karir}

Selanjutnya, Anda perlu membuat rencana dan menjabarkan langkahlangkah yang harus dilakukan untuk mencapai tujuan tersebut. Rencana tersebut sama dengan peta yang bisa membawa Anda mencapai tujuan secara bertahap. Buat sasaran jangka pendek dan jangka panjang serta langkahlangkah yang harus diambil agar bisa mencapai tujuan tersebut. Perhatikan berbagai kendala dan hambatan yang bisa menghalangi Anda untuk mencapai tujuan yang diinginkan.

Motivasi adalah proses yang menjelaskan intensitas, arah, dan ketekunan seorang individu untuk mencapai tujuannya.Tiga elemen utama dalam definisi ini diantaranya adalah intensitas, arah, dan ketekunan.

Berdasarkan teori hierarki kebutuhan Abraham Maslow, teori X dan teori Y Douglas McGregor maupun teori motivasi kontemporer, arti motivasi adalah 'alasan' yang mendasari sebuah perbuatan yang dilakukan oleh seorang individu. Seseorang dikatakan memiliki motivasi tinggi dapat diartikan orang tersebut memiliki alasan yang sangat kuat untuk mencapai apa yang diinginkannya dengan mengerjakan pekerjaannya yang sekarang. Berbeda dengan motivasi dalam pengertian yang berkembang di masyarakat yang sering kali disamakan dengan 'semangat', seperti contoh dalam percakapan "saya ingin anak saya memiliki motivasi yang tinggi". Statemen ini bisa diartikan 


\section{JURNAL ABDIMAS

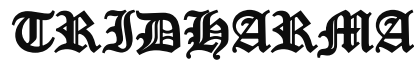

orang tua tersebut menginginkan anaknya memiliki semangat belajar yang tinggi. Maka, perlu dipahami bahwa ada perbedaan penggunaan istilah motivasi di masyarakat. Ada yang mengartikan motivasi sebagai sebuah alasan, dan ada juga yang mengartikan motivasi sama dengan semangat.

Dalam hubungan antara motivasi dan intensitas, intensitas terkait dengan seberapa giat seseorang berusaha, tetapi intensitas tinggi tidak menghasilkan prestasi kerja yang memuaskan kecuali upaya tersebut dikaitkan dengan arah yang menguntungkan organisasi.Sebaliknya elemen yang terakhir, ketekunan, merupakan ukuran mengenai berapa lama seseorang dapat mempertahankan usahanya.

Motivasi berasal dari bahasa Latin "movere", yang berarti menggerakkan. Menurut Weiner (1990) motivasi didefenisikan sebagai kondisi internal yang membangkitkan kita untuk bertindak, mendorong kita mencapai tujuan tertentu, dan membuat kita tetap tertarik dalam kegiatan tertentu. Menurut Uno (2007), motivasi dapat diartikan sebagai dorongan internal dan eksternal dalam diri seseorang yang diindikasikan dengan adanya hasrat dan minat, dorongan dan kebutuhan, harapan dan cita-cita, penghargaan, dan penghormatan. Sedangkan Imron (1966) menjelaskan bahwa motivasi berasal dari bahasa Inggris "motivation" yang berarti dorongan atau pengalasan untuk melakukan suatu aktivitas hingga mencapai tujuan.

Dari serangkain pengertian para ahli di atas, maka dapat disimpulkan bahwa motivasi adalah sesuatu alasan yang mendorong seseorang untuk melakukan; menyelesaikan; menghentikan; dsb, suatu aktivitas guna mencapai tujuan tertentu yang diinginkan dari motivasi tersebut.

Teori motivasi yang paling terkenal adalah Teori

Hierarki
Kebutuhan milik Abraham Maslow. ${ }^{[3]}$ Ia membuat hipotesis bahwa dalam setiap

diri manusia terdapat hierarki dari lima kebutuhan, yaitu fisiologis (rasa lapar, haus, seksual, dan kebutuhan fisik lainnya),

rasa aman (rasa ingin dilindungi dari bahaya fisik dan emosional), sosial (rasa kasih sayang, kepemilikan, penerimaan, dan persahabatan), penghargaan (faktor penghargaan internal dan eksternal), dan aktualisasi diri (pertumbuhan, pencapaian potensi seseorang, dan pemenuhan diri sendiri).

Maslow memisahkan lima kebutuhan ke dalam urutan-urutan.Kebutuhan fisiologis dan rasa aman dideskripsikan sebagai kebutuhan tingkat bawah sedangkan kebutuhan sosial, penghargaan, dan aktualisasi diri sebagai kebutuhan tingkat atas.Perbedaan antara kedua tingkat tersebut adalah dasar pemikiran bahwa kebutuhan tingkat atas dipenuhi secara internal sementara kebutuhan tingkat rendah secara dominan dipenuhi secara eksternal.

Teori kebutuhan Maslow telah menerima pengakuan luas di antara manajer pelaksana karena teori ini logis secara intuitif. Namun, penelitian tidak memperkuat teori ini dan Maslow tidak memberikan bukti empiris dan beberapa penelitian yang berusaha mengesahkan teori ini tidak menemukan pendukung yang kuat.

\section{Teori X dan teori Y}

Douglas McGregor menemukan teori X dan teori $Y$ setelah mengkaji cara para manajer berhubungan dengan para karyawan.Kesimpulan yang didapatkan adalah pandangan manajer mengenai sifat manusia didasarkan atas beberapa kelompok asumsi tertentu dan bahwa mereka cenderung membentuk perilaku mereka terhadap karyawan berdasarkan asumsi-asumsi tersebut. 


\section{JURNAL ABDIMAS

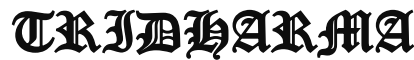

Ada empat asumsi yang dimiliki manajer dalam teori $\mathrm{X}$.

- Karyawan pada dasarnya tidak menyukai pekerjaan dan sebisa mungkin berusaha untuk menghindarinya.

- Karena karyawan tidak menyukai pekerjaan, mereka harus dipakai, dikendalikan, atau diancam dengan hukuman untuk mencapai tujuan.

- Karyawan akan mengindari tanggung jawab dan mencari perintah formal, di mana ini adalah asumsi ketiga.

- Sebagian karyawan menempatkan keamanan di atas semua faktor lain terkait pekerjaan dan menunjukkan sedikit ambisi.
Bertentangan dengan pandangan- pandangan negatif mengenai sifat manusia dalam teori $X$, ada pula empat asumsi positif yang disebutkan dalam teori $\mathrm{Y}$.

- Karyawan menganggap kerja sebagai hal yang menyenangkan, seperti halnya istirahat atau bermain.

- Karyawan akan berlatih mengendalikan diri dan emosi untuk mencapai berbagai tujuan.

- Karyawan bersedia belajar untuk menerima, mencari, dan bertanggungjawab.

- Karyawan mampu membuat berbagai keputusan inovatif yang diedarkan ke seluruh populasi, dan bukan hanya bagi mereka yang menduduki posisi manajemen.

Pengertian, Visioner, Tegas, Bijaksana Bisa menempatkan diri, Mampu/cakap Terbuka, Mampu mengatur, Disegani, Cerdas, Cekatan, Terampil, Pemotivasi, Jujur, Berwibawa, Berwawasan luas, Konsekuen, Melayani, Credible, Mampu membawa perubahan, Adil, Berperikemanusiaan, Kreatif, Inovatif, Sabar, Bertanggung jawab, Konsiten, Low profile, Sederhana dan humble (rendah hati), Rendah hati/humble, Royal/tidak kikir, berjiwa sosial Loyal (setia) kepada bawahan, Disiplin,
Mampu menjadi tauladan/memberi contoh, Punya integritas, Berdikasi/berjiwa mengabdi, Dapat dipercaya (credible), Percaya diri, Kritis, Religious, Mengayomi, Responsive (cepat tanggap), Teliti, Supel (ramah), Pema'af, Peduli (care), Profesional, Berprestasi, Penyelesai Masalah (problem solver), Good looking, Sopan, Cerdas secara emosi (memiliki tingkat EQ yang tinggi

Teori motivasi kontemporer

Teori motivasi kontemporer bukan teori yang dikembangkan baru-baru ini, melainkan teori yang menggambarkan kondisi pemikiran saat ini dalam menjelaskan motivasi

karyawan. ${ }^{[4]}$ Teori motivasi kontemporer mencakup teori-teori berikut.

\section{Teori kebutuhan McClelland}

Teori kebutuhan McClelland dikembangkan oleh David McClelland dan teman-temannya.Teori kebutuhan McClelland berfokus pada tiga kebutuhan yang didefinisikan sebagai berikut:

- kebutuhan berprestasi: dorongan untuk melebihi, mencapai standar-standar, berusaha keras untuk berhasil.

- kebutuhan berkuasa: kebutuhan untuk membuat individu lain berperilaku sedemikian rupa sehingga mereka tidak akan berperilaku sebaliknya.

- kebutuhan berafiliasi: keinginan untuk menjalin suatu hubungan antarpersonal yang ramah dan akrab.

\section{Teori evaluasi kognitif}

Teori evaluasi kognitif adalah teori yang menyatakan bahwa pemberian penghargaan-penghargaan ekstrinsik untuk perilaku yang sebelumnya memuaskan secara intrinsik cenderung mengurangi tingkat motivasi secara keseluruhan. Teori evaluasi kognitif 


\section{JURNAL ABDIMAS

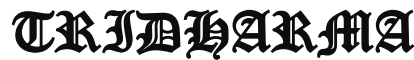

telah diteliti secara eksensif dan ada banyak studi yang mendukung.

\section{Teori penentuan tujuan}

Teori penentuan tujuan adalah teori yang mengemukakan bahwa niat untuk mencapai tujuan merupakan sumber motivasi kerja yang utama. Artinya, tujuan memberitahu seorang karyawan apa yang harus dilakukan dan berapa banyak usaha yang harus dikeluarkan.

\section{Teori penguatan}

Teori penguatan adalah teori di mana perilaku merupakan sebuah fungsi dari konsekuensi-konsekuensinya jadi teori tersebut mengabaikan keadaan batin individu dan hanya terpusat pada apa yang terjadi pada seseorang ketika ia melakukan tindakan.

\section{Teori Keadilan}

Teori keadilan adalah teori bahwa individu membandingkan masukanmasukan dan hasil pekerjaan mereka dengan masukan-masukan dan hasil pekerjaan orang lain, dan kemudian merespons untuk menghilangkan ketidakadilan.

\section{Teori harapan}

Teori harapan adalah kekuatan dari suatu kecenderungan untuk bertindak dalam cara tertentu bergantung pada kekuatan dari suatu harapan bahwa tindakan tersebut akan diikuti dengan hasil yang ada dan pada daya tarik dari hasil itu terhadap individu tersebut.

\section{Area motivasi manusia}

Empat area utama motivasi manusia adalah makanan, cinta, seks, dan pencapaian.Tujuan-tujuan yang mendasari motivasi ditentukan sendiri oleh individu yang melakukannya, individu dianggap tergerak untuk mencapai tujuan karena motivasi intrinsik (keinginan beraktivitas atau meraih pencapaian tertentu semata-mata demi kesenangan atau kepuasan dari melakukan aktivitas tersebut), atau karena motivasi ekstrinsik, yakni keinginan untuk mengejar suatu tujuan yang diakibatkan oleh imbalan-imbalan eksternal. disamping itu terdapat pula faktor yang lain yang mendukung diantaranya ialah faktor internal yang datang dari dalam diri orang itu sendiri.

\section{KESIMPULAN DAN SARAN Kesimpulan}

Bersama Kelurahan Pondok Benda berhasil membantu meningkatkan kesadaran remaja setempat untuk mengikuti program- program dalam pengembangan diri, Bersama Kelurahan Pondok Benda membantu sebagian kesulitan dalam merencanakan karier., Bersama Kelurahan Pondok Benda cukup berhasil meningkatkan kekuatan moril sebagian Remaja yang sudah sangat menurun tentang sulitnya pengembangan diri. Bersama Kelurahan Pondok Benda cukup berhasil membantu masyarakat dalam membangun pola pikir agar masyarakat dapat mengembangkan ide dan kreativitasnya.

\section{Saran}

Situasi ini akan terus menerus menjadi penghalang jika tidak ada perubahan Remaja, untuk itu dibutuhkan keberlanjutan

program-program seperti ini di masa yang akan dating.

\section{DAFTAR PUSTAKA}

Elder Jr, G. H., Conger, R. D., Foster, E. M., \& Ardelt, M. (1992). Families under economic pressure. Journal of Family issues, 13(1), 5-37. 


\section{JURNAL ABDIMAS

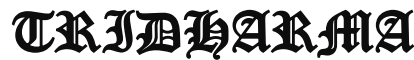

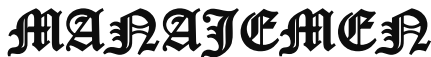

Kerkmann, B. C., Lee, T. R., Lown, J. M., \& Allgood, S. M. (2000). Financial management, financial problems and marital satisfaction among recently married university students. Journal of Financial Counseling and Planning, 11(2), 55.

Leinonen, J. A., Solantaus, T. S., \& Punamäki, R. L. (2002). The specific mediating paths between economic hardship and the quality of parenting. International journal of behavioral development, 26(5), 423-435.

Pasaribu, V. L. D., Susanti, F., \& Hartuti, E. T. K. (2019). Memotivasi Siswa dan Siswi SMK Letris Indonesia di Dalam Menentukan Pilihan Untuk Melanjutkan Pendidikan Atau Bekerja Setelah Lulus Sekolah. Jurnal Pengabdian Dharma Laksana, 1(2), 161-172.

Pasaribu, V. L. D., Agrasadya, A., Shabrina, N., \& Krisnaldy, K. (2020). MENJADI ENTERPRENEUR MUDA YANG MEMILIKI JIWA LEADERSHIP UNTUK MENGHADAPI MASA DEPAN. Abdi Laksana, 1(1).

Pasaribu, V. L. D., Elburdah, R. P., Sudarso, E., \& Fauziah, G. (2020). PENGGUNAAN MANAJEMEN WAKTU TERHADAP PENINGKATAN PRESTASI BELAJAR DI SMP ARAISIYAH. Jurnal ABDIMAS Tri Dharma Manajemen, 1(1).

Pasaribu, V. L. D., Sulaiman, S., Sutiman, S., Thaharudin, T., \& Purnomo, B. Y. (2020). PENGENALAN LETAK POSYANDU TERDEKAT DIKELURAHAN PISANGAN DENGAN MANAJEMEN PEMASARAN REVOLUSI 4.0 UNTUK MENINGKATKAN PENGETAHUAN MASYARAKAT LETAK DAN FUNGSI POSYANDU TERDEKAT PADA KELURAHAN PISANGAN. DEDIKASI PKM, I(1), 105-110.
Pasaribu, V. L. D., Oktrima, B., Prabowo, B., Arianto, N., \& Haryoko, U. B. (2020). PROGAM PENDAMPINGAN DAN PENYELENGGARAAN PENDIDIKAN ANAK PADA USIA DINI TERHADAP PRESTASI BELAJAR DILINGKUNGAN RT 020 RW 009. KEL GIRI PENI. KEC WATES. YOGYAKARTA. JURNAL LOKABMAS KREATIF, 1(1), 71-75

Parrota, J. L., \& Johnson, P. J. (1998). The impact of financial attitudes and knowledge on financial management and satisfaction of recently married individuals. Financial Counseling and Planning,9(2), 59-75.

Raharjo, I. T., Puspitawati, H., \& Krisnatuti, D. (2015). Tekanan ekonomi, manajemen keuangan, dan kesejahteraan pada keluarga muda. Jurnal Ilmu Keluarga \& Konsumen, 8(1), 38-48.

Robila, M., \& Krishnakumar, A. (2005). Effects of economic pressure on marital conflict in Romania. Journal of Family Psychology, 19(2), 246.

Skogrand, L., Johnson, A. C., Horrocks, A. M., \& DeFrain, J. (2011). Financial management practices of couples with great marriages. Journal of family and economic issues, 32(1), 27-35.

Sunoto, I., \& Nulhakim, A. L. (2017). Mengukur Tingkat Partisipasi Pemuda Dalam Program Karang Taruna dengan Pendekatan Metode Fuzzy Infrence System Mamdani. Simetris: Jurnal Teknik Mesin, Elektro dan Ilmu Komputer, 8(2), 711-720.

Astuti, W. (2020) . Pengaruh kepemimpinan dan disiplin kerja terhadap kinerja karyawan pada PT Indosat TBK Jakarta Selatan. Jurnal Semarak, Vol 3 No 2, 102- 112

DOKUMENTASI KEGIATAN 
JURNAL ABDIMAS

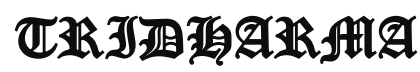

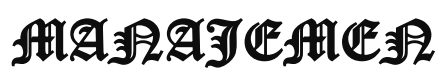

\section{P-ISSN 2715-7105, E-ISSN 2716-070X}

Jurnal ABDIMAS Vol. 2, No. 1,Januari 2021,Hal (103-111)

@Prodi Manajemen Fakultas Ekonomi Universitas Pamulang

Email: abdimasjurnal.unpam@ gmail.com Telp: (021) 741-2566
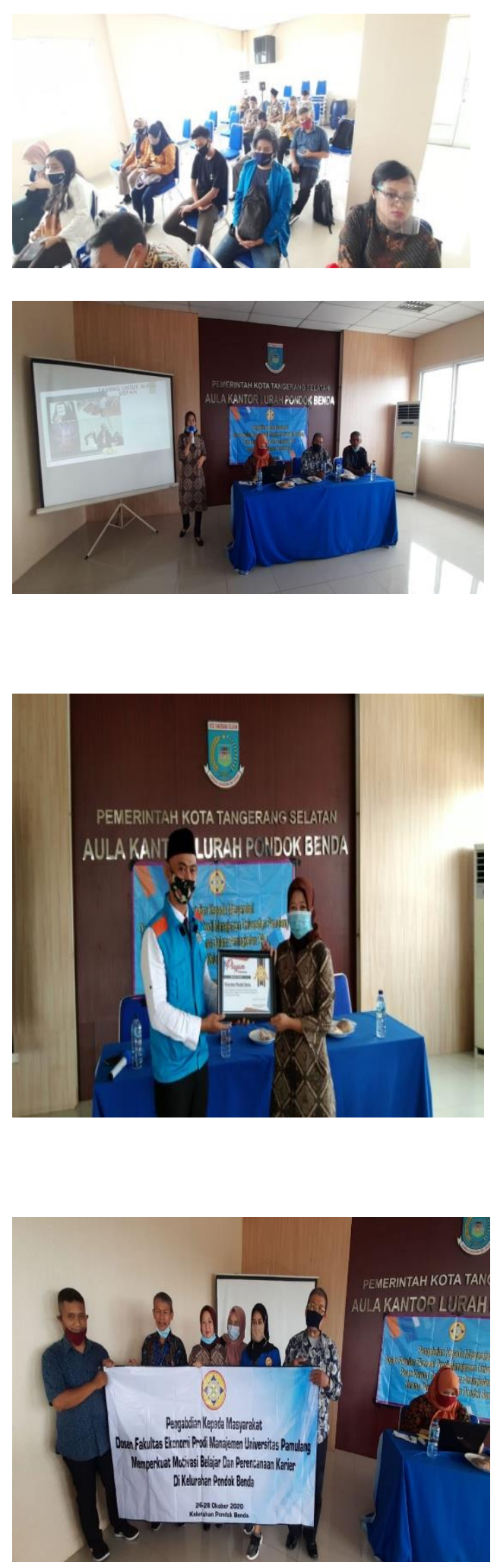